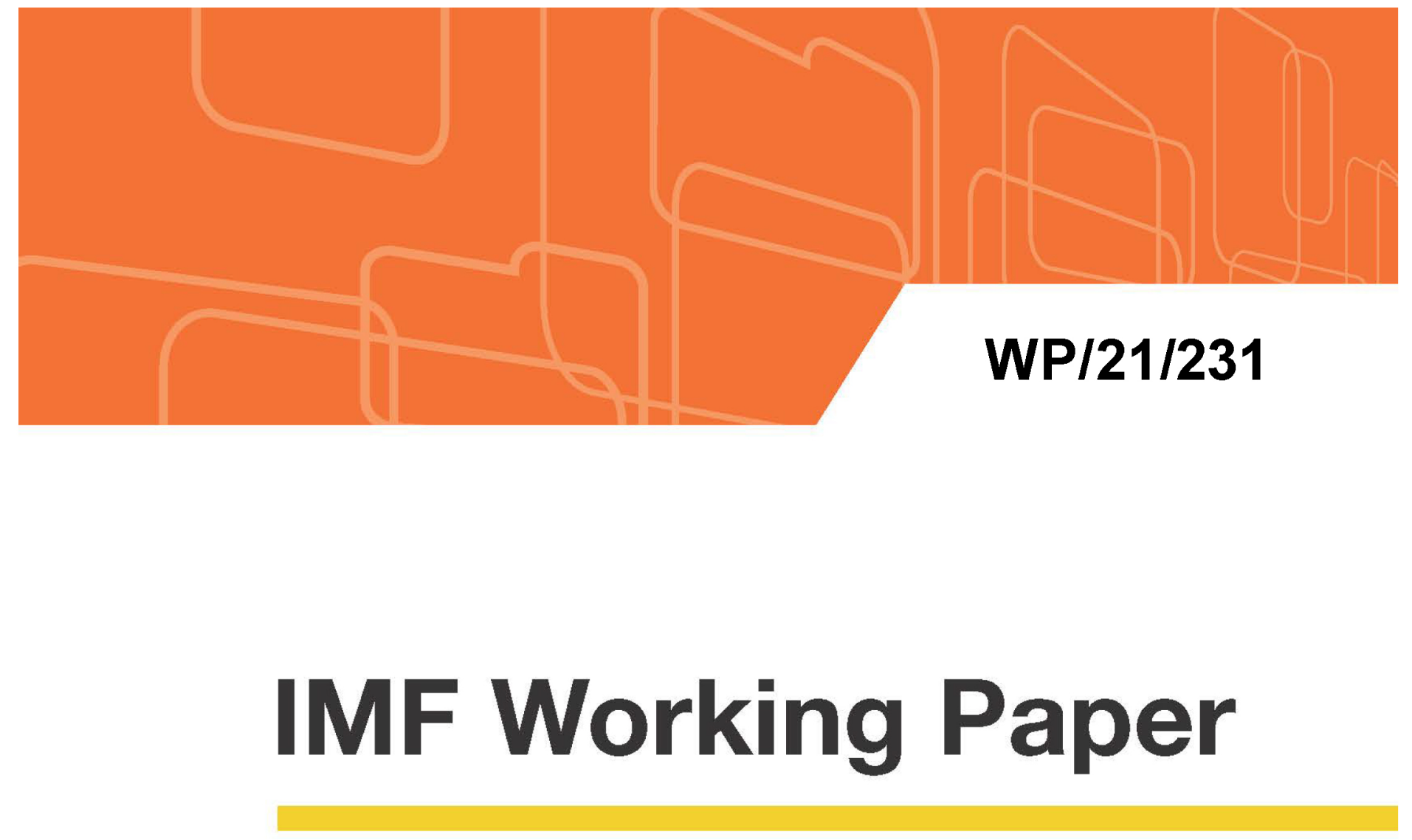

\title{
Enhancing Tax Compliance in the Dominican Republic Through Risk-based VAT Invoice Management
}

by Cristian Alonso, Ledys Feliz, Patricia Gil, and Miguel Pecho

IMF Working Papers describe research in progress by the author(s) and are published to elicit comments and to encourage debate. The views expressed in IMF Working Papers are those of the author(s) and do not necessarily represent the views of the IMF, its Executive Board, or IMF management. 


\title{
IMF Working Paper
}

Fiscal Affairs Department

\section{Enhancing Tax Compliance in the Dominican Republic Through Risk-based VAT Invoice Management}

\author{
Prepared by Cristian Alonso, Ledys Feliz, Patricia Gil, and Miguel Pecho \\ Authorized for distribution by James Daniel and Andrew Masters
}

September 2021

IMF Working Papers describe research in progress by the author(s) and are published to elicit comments and to encourage debate. The views expressed in IMF Working Papers are those of the author(s) and do not necessarily represent the views of the IMF, its Executive Board, or IMF management.

\begin{abstract}
Invoices document economic transactions and are thus critical to assess tax liabilities. We study a reform in the Dominican Republic that aimed to integrate invoice management into a broader, more comprehensive, risk-based compliance strategy. By rationing authorized invoices based on an extra scrutiny of each taxpayer's compliance history, the reform led to significant and persistent improvements on filing, payment, and information reporting obligations and a modest increase in reported tax liabilities. Our study shows that deterrence effects over compliance behaviors are strengthened when the tax administration makes explicit and active use of taxpayers' information, no matter if the invoicing framework is paper-based or electronic.

JEL Classification Numbers: D22, H25, H26, H32

Keywords: Invoicing, VAT, Tax Compliance, Risk-Based

Authors' E-Mail Addresses: calonso@imf.org, Icfeliz@dgii.gov.do, pagil@dgii.gov.do, mpecho@imf.org
\end{abstract}

\footnotetext{
${ }^{1}$ We are grateful for excellent comments from Hassan Adan, Katherine Baer, Matthieu Bellon, James Daniel, Paulo Dos Santos, Gustavo González Amilivia, José Maria Pires, Graham Whyte, and participants at the FAD seminar series.
} 
TABLE OF CONTENTS

PAGE

I. INTRODUCTION

$\underline{4}$

II. A RISK-BASED RATIONING OF INVOICES _ $\underline{\mathbf{6}}$

A. Background _

B. Description of the Reform _

III. DATA _

IV. IDENTIFICATION STRATEGY

V. RESULTS

A. Filing Obligations__ 14

B. Payment Obligations _

C. Tax Liabilities__

D. Information Reporting Obligations__ $\underline{21}$

VI. CONCLUSION _ 23

BOXES

1. VAT Invoice Management in Latin America __

FIGURES

1. Impact of the Reform on the Approval of Invoices

2. Impact on Compliance with Filing Obligations - First Phase__

3. Short-Term Impact on Tax Collections__

4. Impact on VAT Liability__ $\underline{\underline{20}}$

5. Short-Term Impact on Compliance with Information

Reporting Obligations - First Phase __ 22

\section{TABLES}

1. Summary Statistics

2. Impact on Tax Collections by Taxpayer Size___

3. Impact on Income Tax Liability by Taxpayer Size___

4. Medium-Term Impact on Compliance with Information

Reporting Obligations

APPENDIX

A. Filing Obligations in the Second Phase of the Reform

B. Information Reporting Obligations in the Second Phase of the Reform

C. Robustness

$\underline{29}$ 


\section{INTRODUCTION}

Invoices document economic transactions, which makes them critical to assess tax liabilities or verify tax deductions, credits, and refunds in value-added tax (VAT). Latin American tax administrations have long acknowledged the central role of invoices and have opted for a relatively tight management approach. Their approach includes: i) regulating the characteristics of every VAT invoice circulating in the economy, ii) authorizing the quantity of invoices that businesses can use for their economic transactions, and iii) enforcing invoice issuance and bookkeeping. Despite such a tight management approach, many tax administrations are not taking full advantage of all the information they have on each taxpayer, particularly the level of their compliance risks, to improve invoice management. In this paper, we study a revenue administration reform in the Dominican Republic that introduced risk-based rationing of invoices and evaluate its impact on VAT and income tax compliance.

The Dominican Republic introduced risk-based rationing of invoices in 2018. ${ }^{2}$ Invoices that the tax administration had approved but that businesses had not issued before May 2018 were declared void after this date, so that all VAT-registered taxpayers had to request approval for new invoices starting in April 2018. From there onwards, the tax administration rejected invoice requests or approved only a fraction of the invoices requested by businesses based on their tax compliance history. In the first phase of the reform, the tax administration's response depended on compliance with filing and information reporting obligations. In the second phase of the reform, starting in January 2019, the response was also based on pending payment obligations, that is tax arrears.

We evaluate the reform by comparing taxpayers' outcomes around the time they requested invoices depending on whether their request was approved or rejected by the tax administration. In the first phase of the reform, while all taxpayers had to request new invoices starting in April 2018, not all taxpayers received the same treatment. Our identification strategy leverages that some taxpayers got their requests approved whereas others did not. We use a specification with fixed effects to capture constant taxpayers' characteristics and common time trends. Our main specifications are estimated at daily and monthly frequency, which lends high credibility to our identification strategy. For monthly specifications, we allow for flexible parametric time trends to differ across treatment and control too. For the second phase of the reform, we focus on taxpayers with tax arrears, with the treatment group being those taxpayers who got their requests denied after January 2019 and the control group having received approval for their requests before January 2019.

\footnotetext{
${ }^{2}$ The Dominican Republic has a paper-based invoicing framework, although it is working on implementing einvoicing. The findings of this paper apply both to paper-based and electronicinvoicing frameworks. In fact, electronic invoicing could make it easier to enact this type of reform by lowering the costs of compliance.
} 
We find that the reform led to an improvement in compliance with filing and information reporting obligations. ${ }^{3}$ The probability of past-due filing of VAT returns and information returns detailing invoices issued and received rose sharply by almost 10 percentage points on the day of the rejection, in the first phase of the reform. This improvement was persistent. The increase in timely filing of VAT and information returns remained positive and significant into the medium term. The results were larger for the second phase of the reform. The probability of filing income tax returns also increased sharply. In addition, the Dominican authorities reported improvements in the accuracy of registered taxpayer information. These results are important because compliance with these obligations helps tax authorities collect information which in turn can be used to further target interventions. In part, the improved compliance with filing and information reporting obligations may reflect the fact that the limited number of invoices approved means a recurrent need for taxpayers to return to the tax administration with requests for additional invoices, and so they have an extra incentive to comply. But they may also be explained by enhanced salience of these obligations if taxpayers are inattentive (Chetty, Looney, and Kroft, 2009; Chirico et al., 2016). The reform may have demonstrated to taxpayers that the tax administration was paying attention to their behavior, increasing the incentives to comply.

The reform yielded moderate increases in tax liabilities. In the first phase of the reform, output VAT rose more than input VAT in the first two months after rejection, leading to a small increase in net VAT liability, although not significant. Growth in input VAT accelerated later on, suggesting that taxpayers were quick to gather additional sources to offset their tax liability, which in itself may be positive for strengthening the VAT self-enforcement chain over time. The impact on VAT liability was significantly larger in the second phase of the reform. Income tax liability for small (SME) taxpayers increased by 7 percent, while remaining unchanged for large taxpayers. ${ }^{4}$

The reform also resulted in an increase in VAT collections. In the first phase of the reform, the probability of VAT payments rose by 2 percentage points on the day of the rejection, reflecting equally timely and past-due payments. Interestingly, at this stage, tax arrears were not part of the rationing algorithm. Nevertheless, taxpayers felt compelled to pay their debts anyways. In the second phase of the reform, when tax arrears were included as part of the rationing algorithm, the probability of VAT payments increased by 4.3 percentage points among treated taxpayers, entirely due to the payment of past-due taxes. Small (SME) taxpayers increased their amount paid by 2.4 percentage points on average during the first phase of the reform. There was no

\footnotetext{
${ }^{3}$ Taxpayers required to file tax returns according to tax legislation, shall file tax returns by the deadlines established by the tax administration. Filing of tax returns remains a principal means by which a taxpayer's tax liability is established and becomes due and payable. On the other hand, if required by the tax administration, any person (taxpayers or not) are obligated to submit (periodically) tax information returns, either as part of withholding obligations or a separate stand-alone requirement in respect of own operations or concerning another person's. Information reporting is valuable for ensuring accurate reporting by taxpayers on tax returns though systematic crosschecking of information. For the purpose of this paper, we focus on information reporting of invoices issued due to sales and invoices received due to purchases.

${ }^{4}$ Our estimates for monetary changes are obtained from log linear specifications (unless otherwise specified), so they correspond to log percentage points. For simplicity of exposition, we refer to them as percent.
} 
significant response in amounts paid among large taxpayers, including in the second phase, which is in line with previous findings of relatively stronger compliance among large taxpayers (Ebrill et al., 2001).

Our paper contributes to the literature on tax enforcement by studying the potential role of riskbased tools for the strengthening of revenue administration functions. ${ }^{5}$ Digitalization reforms in tax administration have raised significant attention recently, particularly due to the introduction of electronic fiscal devices (Casey and Castro, 2015) and electronic invoicing or e-invoicing (Artana and Templado, 2018; Barreix and Zambrano, 2018; Bellon et al., 2019; Bérgolo et al., 2018; Castro et al., 2016; Okunogbe and Pouliquen, 2018; Ramírez et al., 2018) with findings of positive impact on compliance and tax liabilities. ${ }^{6}$ Risk-based tools are widely viewed as core components of a modern tax administration (Russell, 2010; TADAT, 2019), yet their use in invoice management has not been studied. We fill this gap by studying a rationing reform that leveraged risk-based tools and that could be applied both to paper-based and electronic invoicing schemes. ${ }^{7}$ And we show that explicit and active use of taxpayers' information can lead to large gains in compliance.

The rest of the paper is structured as follows. In Section II we provide the institutional details of the rationing reform. The rich administrative data used for the analysis is presented in Section III. Section IV discusses our identification strategy to measure the impact of the reform. Section V presents our main results on the improvement in compliance with filing and information reporting obligations, tax collections, and tax liabilities. Finally, Section VI concludes.

\section{A RISK-BASED RATIONING OF INVOICES}

In this section, we describe a reform in the Dominican Republic that strengthened invoice management by introducing a risk-based rationing of invoices approved by the tax administration.

\section{A. Background}

Invoices are a critical component of VAT administration, particularly in Latin America. VAT invoices allow the documentation of economic transactions along the supply chain and provide the basis for computing VAT and income tax liabilities. Perhaps concerned about low tax morale and high informality in the region that increase the risk of false invoicing, tax administrations in Latin America have adopted active invoice management approaches to ensure the integrity of invoices circulating in the economy, including by regulating their format and information included in invoices, authorizing the quantity of invoices that a taxpayer can use for their

\footnotetext{
${ }^{5}$ Slemrod (2019) offers a comprehensive review of the recent body of research on tax compliance and enforcement.

${ }^{6}$ Recent work on tax administration reforms to enhance compliance and strengthen the VAT self-enforcing chain also include Carrillo et al. (2017), Naritomi (2019), and Pomeranz (2015).

${ }^{7}$ Our paper builds on DGII (2019).
} 
transactions and enforcing invoice issuance and book-keeping (Box 1). Thus, in Latin America, taxpayers must first request approval of invoices by the tax administration before being able to issue those invoices to customers when they sell their products or services.

Prior to the reform, the Dirección General de Impuestos Internos (DGII, that is, the Dominican tax administration) had adopted a sound framework to enforce invoice authorization, issuance, and bookkeeping. Key components of this approach included: i) standardization of invoice format, including minimum information requirements and mandatory use of sequential numbering; ii) differentiated treatment for invoices that entitle taxpayers to claim credits, deductions, and refunds (mostly B2B, that is, business to business), iii) extensive information reporting obligations to report VAT invoices issued and received, combined with mandatory use of electronic fiscal devices for transactions with final consumers, and iv) certification of printing companies authorized to print paper invoices. More recently, the DGII has digitalized most VAT invoice management procedures and started phasing in electronic invoicing in the country.

The main flaw of the Dominican Republic framework was that VAT invoice management was conducted in isolation rather than as part of an integrated approach to manage compliance risks. For instance, taxpayers' compliance history was not leveraged when authorizing the quantity of invoices requested by taxpayers. Newly registered taxpayers received invoice authorizations without proper due diligence process to assess their risk levels. As authorized invoices were valid indefinitely, taxpayers disappeared from the radar of the tax administration after receiving an authorization, increasing the risk of fictitious credits, deductions, and refunds. As a result, the economy became plagued by fake invoices that facilitated fraudulent practices in VAT and income tax. ${ }^{8}$ Enforcing invoice authorization, issuance, and book-keeping could have benefited from a smart, integrated use of taxpayer information across all core tax functions. Having this integrated focus is one of the keys to effective compliance risk management. And it was in this direction, that the DGII's reform proceeded.

\section{Box 1. VAT Invoice Management in Latin America}

Invoice management has long been a major pillar of strategies to improve compliance in most Latin American tax administrations due to the weak documentation and accounting practices in their economies. The need for effective invoice management was further deepened with the widespread introduction of VAT in the 1980s. Because VAT liabilities are determined based on the difference between input and output VAT as documented by invoices, tax administrations endeavored to track the veracity of invoices circulating in the economy.

\footnotetext{
${ }^{8}$ Despite strong economic growth, VAT and CIT compliance gaps remained unchanged in the lead up to the reform. In the 2014-2017 period, the former remained around 44 percent with respect to potential collection, while the latter was around 62 percent, while GDP growth averaged 6.3 percent.
} 


\section{Box 1. VAT Invoice Management in Latin America (cont.)}

Chile (1976), Bolivia (1987), Mexico (1989), Argentina and Peru (1992), Brazil (1995),

Panama (1996), Venezuela (1999), Ecuador (2002), Colombia (2005), and the Dominican Republic (2007) have implemented these types of controls (Cardoza and Aybar, 2014). ${ }^{9}$ In all these countries, the tax procedure codes (or equivalent legislation) provide broad powers to the tax administrations to regulate the authorization, issuance, and registration of invoices. In addition, the legal framework of taxes such as VAT and income tax explicitly provide for the repudiation of tax credits, deductions, and refunds to taxpayers in cases in which the invoices that support them do not comply with the regulations issued by the tax administrations. This approach has not only contributed to the fight against tax evasion but has also made it possible to improve documentation and accounting practices across the economy, allowing for stronger legal claims on the rights and obligations derived from agreements between parties.

\section{B. Description of the Reform}

In early 2018 the DGII decided to cancel every non-issued invoice forcing new applications for all registered taxpayers. ${ }^{10}$ With all procedures digitalized, applications for new invoices started to be pre-validated online. The pre-validation included verifying if applicants were entitled to request invoices based on the type of customers they served (e.g., final consumers, businesses under free-trade zones, non-residents, the public sector, foreign markets, non-registered businesses, among others) and if the type and the quantity of invoices requested was commensurate to the taxpayers' industry and tax obligations. It also verified if taxpayers were tagged, for instance, as inactive or dormant, as not localized or as high-risk taxpayer due to, for instance, i) not being reported on by withholding agents or third-party information providers, ii) filing null returns recurrently, iii) being identified as a shell company, iv) having ignored examination/verification appointments at the DGII in the past, or v) having been blocked by DGIl's tax auditors because of irregular use of invoices.

The key component of the reform was the rationing of the quantity of invoices requested by taxpayers based on their tax compliance history. A new algorithm was introduced into the system combining information of the stock of invoices non-issued by the taxpayer (based on information reported by others), the average rate of invoice issuance of previous years, and a taxpayers' compliance score. The taxpayers' compliance score (between 0 and 1) reflected an assessment of compliance with VAT and income tax filing obligations, both of tax returns and information returns of invoices issued due to sales and received due to purchases. In January 2019, as part of the second phase of the reform, compliance with payment obligations including

\footnotetext{
${ }^{9}$ Number in parenthesis refers to the year in which invoicing controls were introduced.

${ }^{10}$ The reform was formally enacted by Norma General 2018-06 issued on February 1, 2018. Non-issued invoices would become void after May 1, 2018. Taxpayers could request new invoices starting on April 2 (large taxpayers), April 9 (small corporations), and April 16 (other taxpayers).
} 
instalment plans was incorporated into the algorithm. In the case of new registered taxpayers, the reform granted approval for a small number of invoices as they were classified as of highrisk. Finally, the reform introduced a period of validity of two years for all invoices.

The rationing of invoices based on the taxpayers' arrears implemented in the second phase of the reform is a novel strategy developed by the DGII. Of course, it aims to increase tax collection and give additional incentives to taxpayers to pay on timely basis. It could be argued that this strategy unduly burdens taxpayers experiencing weak cash flows. However, tax arrears keep growing in the Dominican Republic, reaching 7.6 percent of GDP in 2020, and other planned structural reforms will take time to be effective in addressing these challenges. ${ }^{11}$

If their request for invoices is rejected, taxpayers can resubmit their applications once they resolved the issue that led to the rejection. For instance, taxpayers may need to update their registration information, file past-due tax returns, submit information returns, amend VAT or income tax returns, and pay or apply for payment plans for their tax arrears, among others.

The reform led to substantial rationing of invoices (Figure 1). Before April 2018, no applications for invoices were rejected and all the invoices requested by taxpayers were approved. After the reform came into effect in April, the number of rejections soared and the DGll started approving only a fraction of the invoices requested. On April 9, 2018, when small corporations could request new invoices, the number of rejections peaked at 3,642. The number of rejections declined, but remained significant after May 2018. The share of invoices approved (as percent of those requested) declined to about 20 percent in the first weeks of the reform and recovered afterwards, oscillating between 40 and 50 percent ever since, well below the 100 percent prereform level.

\footnotetext{
${ }^{11}$ Several weaknesses in the legal framework contribute to this situation. For example, the taxpayer tends to delay the payment of their tax debts by objecting and/or appealing DGII's adjustments because those actions by the taxpayer do not require partial payment of the debt as a guarantee, as it is the case in other countries. And also because the suspension of the statute of limitations for the collection of these debts is only two years. Given that most tax disputes take more than two years to be resolved, by the time they are finally resolved, it is too late for the DGII to demand payment.
} 
Figure 1. Impact of the Reform on the Approval of Invoices
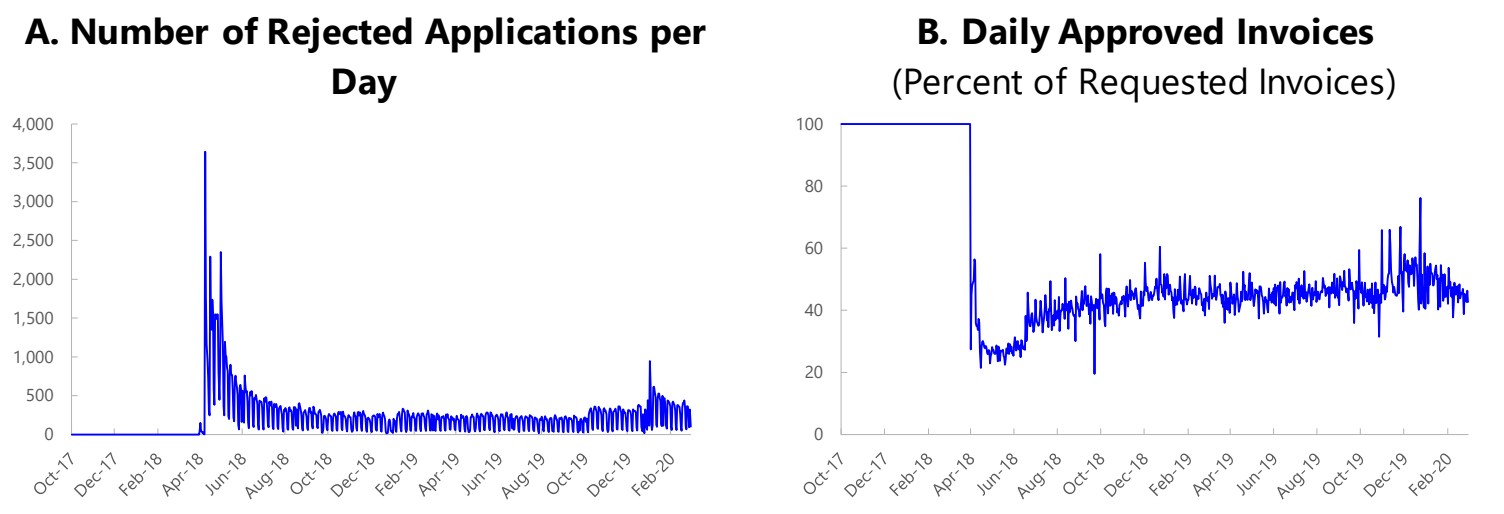

Note: Panel A shows the number of applications for invoices rejected by the DGII each day.

Panel B shows the average across taxpayers of the number of approved invoices as a percent of requested invoices each day. It only includes taxpayers whose request for invoices was approved.

\section{DATA}

In this section, we discuss the rich microdata at the taxpayer lever that we use to evaluate the rationing reform in its two phases.

Administrative data is provided by the DGII and covers a wide range of variables related to treatment, compliance with filing and information reporting obligations, payments, and tax liabilities. In particular, we use:

- Invoice Request. A dataset of each invoice request made by each taxpayer including the date of the request and the decision by the DGII. This allows us to identify precisely when a request for invoices was rejected.

- VAT Returns. A dataset on all the monthly VAT returns filed by the taxpayer, both original and amended, including date of filing, fiscal period to which it corresponds, and amount of input, output, and net VAT.

- VAT Information Returns. A dataset on the date of filing and period for information reporting of invoices received due to purchases and of invoices issued due to sales.

- VAT Payments. A dataset with the date and amount of each VAT payment made by the taxpayer.

- Income Tax Returns. A dataset on all the annual income tax returns filed by the taxpayer, both original and amended, including date of filing, fiscal period to which it corresponds, and amount of revenues, expenditures, net income, and income tax liability.

Our sample period extends between September 2017 and February 2020. It includes 31,366 taxpayers for the first wave of the reform, when the risk-based rationing of invoices was introduced. For the second wave of the reform, when tax arrears were included in the risk-based rationing algorithm, we have 2,924 taxpayers. Table 1 presents summary statistics. 


\section{Table 1. Summary Statistics}

\begin{tabular}{|c|c|c|c|c|c|c|}
\hline & \multicolumn{3}{|c|}{ Phase 1. Rationing of Invoices } & \multicolumn{3}{|c|}{ Phase 2. Adding Tax Arrears } \\
\hline & Control & Treatment & Difference & Control & Treatment & Difference \\
\hline Number of taxpayers & 15,683 & 15,683 & & 1,462 & 1,462 & \\
\hline \multicolumn{7}{|l|}{ (in percent) } \\
\hline Share of SME taxpayers & 95.6 & 95.0 & & 96.4 & 95.9 & \\
\hline Share of taxpayers in agriculture & 1.2 & 1.2 & & 2.3 & 2.5 & \\
\hline Share of taxpayers in industry & 14.5 & 15.1 & & 18.1 & 18.9 & \\
\hline Share of taxpayers in services & 84.2 & 83.7 & & 79.7 & 78.6 & \\
\hline Share of corporate taxpayers & 68.4 & 67.6 & & 76.6 & 75.2 & \\
\hline \multicolumn{7}{|l|}{ (in Dominican pesos) } \\
\hline \multicolumn{7}{|l|}{ Taxables Sales } \\
\hline 10th percentile & 25,923 & 25,031 & & 27,188 & 26,000 & \\
\hline Median & 196,553 & 189,929 & & 193,433 & 180,064 & \\
\hline Mean & 681,754 & 689,114 & & 751,904 & 705,461 & \\
\hline 90th percentile & $1,529,129$ & $1,490,072$ & & $1,481,179$ & $1,276,596$ & \\
\hline \multicolumn{7}{|l|}{ (in percent, before treatment) } \\
\hline \multicolumn{7}{|l|}{ Monthly probability of filing } \\
\hline Timely VAT returns & 0.44 & 0.43 & -0.004 & 0.25 & 0.18 & $-0.069^{\star * *}$ \\
\hline Past-due VAT returns & 0.20 & 0.20 & $-0.005^{\star *}$ & 0.13 & 0.20 & $0.067^{\star \star *}$ \\
\hline \multicolumn{7}{|c|}{ Monthly probability of filing on-time information returns on } \\
\hline Invoices issued & 0.29 & 0.09 & $-0.202^{\star * *}$ & 0.14 & 0.07 & $-0.062^{* * *}$ \\
\hline Invoices received & 0.33 & 0.31 & $-0.016^{* * *}$ & 0.17 & 0.09 & $-0.086^{\star * *}$ \\
\hline \multicolumn{7}{|c|}{ Monthly probability of filing past-due information returns on } \\
\hline Invoices issued & 0.19 & 0.32 & $0.131^{\star * *}$ & 0.13 & 0.22 & $0.083^{* * *}$ \\
\hline Invoices received & 0.26 & 0.23 & $-0.026^{* * *}$ & 0.16 & 0.23 & $0.076^{* * *}$ \\
\hline \multicolumn{7}{|c|}{$\begin{array}{l}\text { first three columns reflect the first phase of the reform, when risk-based rationing of invoices was } \\
\text { ed (April 2018). The last three columns correspond to the second phase of the reform, when tax } \\
\text { carted to be used to determine rationing (January } 2019 \text { ). } \\
\text { Difference" columns refer to statistical significance. } p<0.1{ }^{* *} p<0.05 * * * p<0.01 \text {. } \\
\text { rst phase of the reform, the treatment group includes taxpayers whose first request for invoices afte } \\
m \text { was rejected. Taxpayers in the control group did not get their request for invoices rejected. They } \\
\text { ected into the control group based on propensity score matching. } \\
\text { econd phase of the reform, the treatment group includes all taxpayers with outstanding tax arrears } \\
\text { st request for invoices after January } 2019 \text { was rejected. Taxpayers in the control group also had } \\
\text { ing tax arrears but requested invoices before January } 2019 \text { and their request was approved. They } \\
\text { ected into the control group based on propensity score matching. } \\
\text { her taxpayers and are classified as "normal" by the DGII. }\end{array}$} \\
\hline
\end{tabular}

\section{CInternational Monetary Fund. Not for Redistribution}




\section{IDENTIFiCATION Strategy}

In this section, we describe the identification strategy employed to measure the impact of the reform in its two phases, that is, the introduction of risk-based rationing in April 2018 and the inclusion of tax arrears as a factor determining rationing in January 2019.

We consider a taxpayer to be treated by the first phase of the reform if their first request for invoices under the new scheme was rejected. Because of data processing limitations, we draw a random set of 15,683 taxpayers from the group for the analysis of the first phase of the reform. ${ }^{12}$ In the Appendix, we also consider alternative definitions of treatment, such as whether taxpayers received approval for only a small number of invoices or if they had more than one request for invoices rejected. We find that our results are robust to those alternative definitions of treatment.

We use taxpayers whose first request for invoices was approved as the control group. We select a random sample of these taxpayers using propensity matching score based on size, industry, region, total sales, and taxable sales to ensure that the control group allows for effective control of trends affecting different industries and types of taxpayers. The first two columns of Table 1 show that the treatment and control groups are indeed fairly similar in those dimensions. Naturally, the groups were not similar in their compliance with tax obligations before the reform, with the treatment group being significantly less likely to comply with filing and reporting requirements. The treatment group showed higher probability of past-due reporting of invoices issued, which is a consequence of their much lower timely reporting compared to the control group.

For the second phase of the reform, we focus on taxpayers with outstanding tax arrears, who would be directly affected by the inclusion of tax arrears in the rationing algorithm in January 2019. Taxpayers with tax arrears that requested invoices starting in January 2019 and had their requests rejected constitute the treatment group. They are 1,462 taxpayers. We then draw a sample of taxpayers with tax arrears that requested invoices before January 2019 and whose requests were approved. As before, we use propensity matching score to ensure that control and treatment are similar in terms of size, industry, region, total sales, and taxable sales. Treatment and control groups were again fairly similar in terms of type, size, and industry composition (Table 1). But the treatment group was significantly less likely to comply with filing requirements on time and more likely to comply late.

\footnotetext{
12 This is roughly 45 percent of the 34,582 taxpayers treated by the reform, that is, the taxpayers whose first request for invoices after April 2019 was rejected. For comparison, the total number of active taxpayers in 2018 in the Dominican Republic was 184,360.
} 
We identify the causal impact of the reform by estimating the following fixed-effects specification:

$$
\left.Y_{i, t}=\sum_{j=-m}^{M} \beta_{j} I \text { Treated }_{i, t+j}=1\right)+\kappa_{i}+\tau_{T(t)}+X_{i, t}+\varepsilon_{i, t}
$$

where $i$ identifies the taxpayer and $t$ identifies the time period, which in some specifications is day and in others is month. Variable Treated $_{i, t+j}$ takes the value of one if taxpayer $i$ was treated at time $t+j$, with $I\left(\right.$.) being the indicator function. ${ }^{13}$ For instance, Treated $_{i, t}$ will take the value of one the day or month when the taxpayer's first request for invoices was rejected and at any time afterwards. $\kappa_{i}$ is the taxpayer fixed effect, $\tau_{T(t)}$ is the month fixed effect, and $\varepsilon_{i, t}$ is an error term. For specifications at a daily frequency, we include in $X_{i, t}$ a dummy for the day of the week. For specifications at a monthly frequency, we include in $X_{i, t}$ a cubic trend interacted by whether the taxpayer is treated or not. ${ }^{14}$ Finally, $Y$ is the variable of interest, which includes whether a firm complies with filing and information reporting obligations; whether it pays VAT and the amount paid; monetary variables in its monthly VAT returns such as input, output, and net VAT; and monetary variables in its annual income tax returns such as revenues, expenditures, net income, and tax liability.

The use of panel data allows for the causal identification of the impact of the reforms. We are comparing outcomes for taxpayers around the time they submitted a request for invoices depending on whether their request was approved or denied. Taxpayer fixed effects capture any observable and unobservable fixed characteristics of the taxpayer. Month and day-of-the-week fixed effects absorb any common time trends and seasonality affecting all taxpayers equally, with the similar composition of treatment and control groups providing assurances of an adequate comparison in terms of industry dynamics or shocks to particular types of taxpayers. In addition, the high frequency of our specifications, whereby we look at outcomes around the day of the request for invoices, enhances the credibility of our results being caused by the reform. At lower frequency, such assurances are weaker. And so, for our specifications at a monthly frequency, we allow for differential parametric time trends between treatment and control to flexibly capture different compliance dynamics between the two groups. For instance, if the compliance of the treatment group was improving even before the reform in way that can be approximated by a cubic polynomial, our specification would capture and separate such trend from the effect of the reform.

To estimate the average impact after treatment, we use the following variant of the previous specification:

$$
\left.Y_{i, t}=\beta I \text { Treated }_{i, t}=1\right)+\kappa_{i}+\tau_{T(t)}+X_{i, t}+\varepsilon_{i, t}
$$

\footnotetext{
13 To normalize the results, $\beta_{-1}$ is assumed to be zero, and $\beta_{-m}$ and $\beta_{M}$ capture the cumulative effect before the first lead and after the last lag (Clarke and Schythe, 2020).

${ }^{14}$ We explore also the use of linear, quadratic, and no trends. The results do not change significantly.
} 
where variable Treated $_{i, t}$ takes the value of one if taxpayer $i$ was treated at any point before $t$. All other variables as defined as before.

Standard errors are clustered at the taxpayer level. To mitigate the impact of outliers, variables in Dominican pesos are winsorized at the $1^{\text {st }}$ and $99^{\text {th }}$ percentiles and growth rates are trimmed at the $99^{\text {th }}$ percentile.

\section{RESUlts}

In this section, we present our estimates for the impact of the rationing reform in its two phases. The first phase was the implementation of risk-based rationing in April 2018. The second phase was the inclusion of tax arrears in the rationing mechanism in January 2019 . We evaluate immediate and medium-term outcomes in terms of compliance with the key tax obligations of filing, payment, reporting of tax liabilities, and information reporting. On filing obligations, we focus on the filing of past-due and on-time returns for VAT and income tax. On payment obligations, we study the taxpayer's response in terms of on-time and late payments for VAT. On reporting of tax liabilities, we explore the impact on the amendment of previously reported VAT liabilities and the reporting of new VAT and income tax liabilities. Finally, we look at the taxpayer's compliance with information reporting obligations on invoices issued and received.

The reform appears to have forced the exit of some taxpayers. There were 7,017 taxpayers whose requests for invoices were never approved. The vast majority, 99 percent, were SME taxpayers, with agricultural taxpayers being overrepresented. Both SME and agricultural taxpayers are known to have higher VAT noncompliance rates compared to large enterprises in the nonagricultural sectors (Ebrill et al., 2001). More than half of them had reported no taxable sales and even the $90^{\text {th }}$ percentile of sales was less than a quarter of the same percentile among active taxpayers. Between January and March 2018, they had contributed less than 0.2 percent of VAT collections. It is unlikely that the reform by itself is fully responsible for the exit of these taxpayers. Instead, declining business or engagement with irregular activities may have been the structural cause for their exit, with the reform potentially accelerating it. Nevertheless, this highlights the importance of carefully assessing the impact of tax reforms on compliance costs, particularly in environments of high informality. This group is excluded from all the analysis in the rest of the paper. ${ }^{15}$

\section{A. Filing Obligations}

The reform led to an immediate improvement in filing of past-due VAT returns. The probability of filing at least one VAT return that was past-due increased by 9.7 percentage points the day the taxpayer's request for invoices was rejected, compared to the control group in the first phase of the reform (Figure 2, Panel A). The result is highly significant, both statistically and economically,

\footnotetext{
${ }^{15}$ Anecdotally, some private sector participants agreed on the importance of this reform, but acknowledged that it may have imposed some transaction costs at the beginning, particularly on small taxpayers.
} 
given that it represents almost 50 percent of the average monthly probability of filing past-due returns by the control group. There was a very small, but statistically significant, pre-trend for treated taxpayers in the two weeks leading up to the rejection suggesting that compliance may have been improving slightly, perhaps reflecting taxpayers anticipating the need to regularize their obligations. Yet, the sharp increase on the day of treatment grants credibility to the causality of our estimates. The probability of filing past-due VAT returns declines afterwards becoming non-significant three days after the rejection, which is reasonable given that by then taxpayers would have presumably already regularized all their pending filing obligations. The improvement associated with the second phase of the reform was similar in dynamics, but larger in magnitudes (Figure A.1, Panel A).

Treated taxpayers improved their filing of income tax returns too (Figure 2, Panel B). The probability of filing an original income tax return rose by 4.9 percentage points on the day of the rejection and remained around 1 percentage point higher and statistically significant for the two weeks after the rejection. A small negative pretrend may also point to anticipation effects. The improvement on impact was slightly larger in the second phase of the reform, but it became insignificant soon afterwards (Figure A.1, Panel B).

The improvement in the probability of timely filing of VAT returns is persistent (Figure 2, Panel C). After an increase of 3.8 percent in the probability of filing on-time VAT returns in the month of the rejection for the first phase of the reform, the probability continued to increase reaching 9.6 percent six months later. The second phase of the reform led to a sharper increase on impact, which also stabilized around 10 percentage points (Figure A.1, Panel C).

Filing of past-due VAT returns becomes not significantly different over the medium term (Figure 2, Panel D). The probability of filing past-due VAT returns rises by 10.1 percentage points during the month of the rejection and falls by 1.9 percentage points the following month and 1.4 percentage points the next. The response becomes smaller and not significant afterwards. The drop during the months after the rejection is understandable following the strong filing of pastdue returns that preceded it. And the lack of significance afterwards is consistent with the improved behavior of timely filing of VAT returns. The improvement was larger on impact for the second phase of the reform, and it remained positive and significant over the medium term, albeit at smaller magnitudes (Figure A.1, Panel D). 
Figure 2. Impact on Compliance with Filing Obligations - First Phase

Increase in the Probability of Filing

(in percentage points)

\section{A. Past-Due VAT Returns}

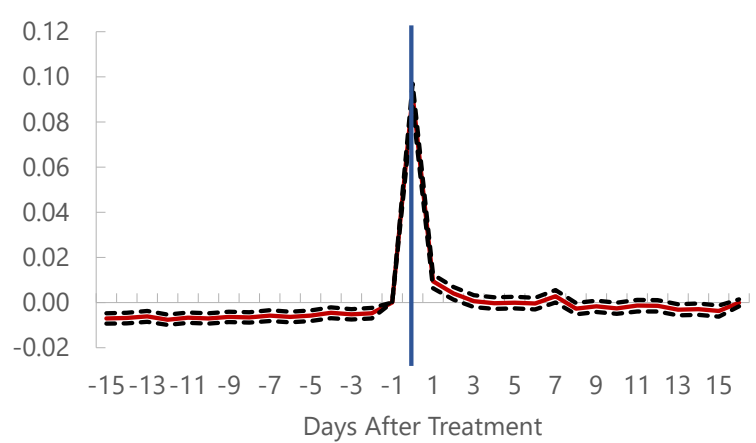

Medium Term

\section{Short Term}

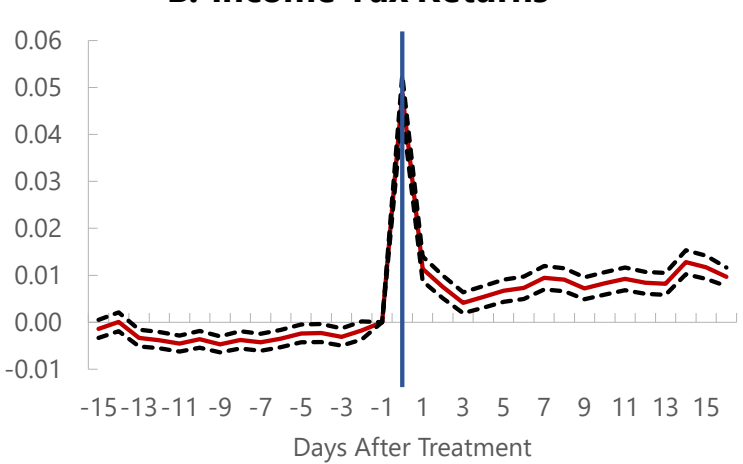

\section{On-Time VAT Returns}

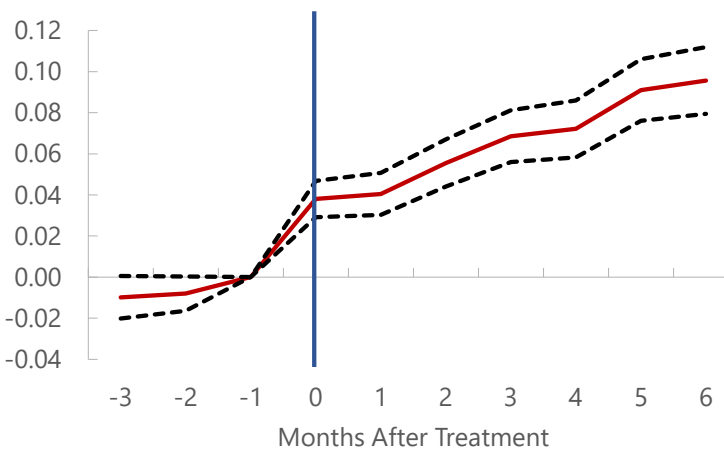

D. Past-Due VAT Returns

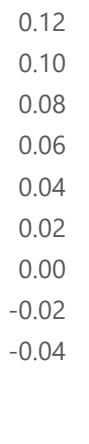

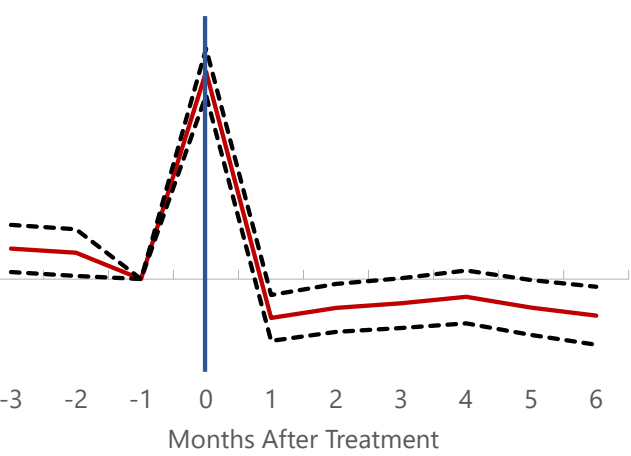

Note: Standard errors clustered by taxpayer. Dashed lines correspond to $95 \%$-level confidence intervals. The short-term results of Panels $\mathrm{A}$ and $\mathrm{B}$ are estimated at a daily frequency with specification $Y_{i, t}=$ $\sum_{j=-16}^{17} \beta_{j} I$ Treated $\left._{i, t+j}=1\right)+\kappa_{i}+\tau_{T(t)}+X_{i, t}+\varepsilon_{i, t}$ where $\tau_{T(t)}$ is a month fixed effect and $X_{i, t}$ includes a dayof-the-week fixed effect. Cumulative effects $\beta_{-16}$ and $\beta_{17}$ not shown.

The medium-term results of Panels $C$ and $\mathrm{D}$ are estimated at a monthly frequency with specification $Y_{i, t}=$ $\sum_{j=-4}^{7} \beta_{j} I\left(\right.$ Treated $\left._{i, t+j}=1\right)+\kappa_{i}+\tau_{T(t)}+X_{i, t}+\varepsilon_{i, t}$ where $\tau_{T(t)}$ is a month fixed effect and $X_{i, t}$ includes a cubic trend interacted by a dummy identifying whether the taxpayer was in the treatment or control group. Cumulative effects $\beta_{-4}$ and $\beta_{7}$ not shown.

\section{B. Payment Obligations}

Treated taxpayers became more likely to pay VAT in the first phase of the reform. On the day of the rejection, treated taxpayers became 2.3 percentage points more likely to make a VAT payment than taxpayers in the control group. The improvement is distributed equally between timely and late payments. In the two weeks leading up to the rejection, there had been no substantial differences in payments between the two groups. 
While both on-time and past-due VAT payments improved, their dynamics were different (Figure 3, Panels A and B). Both rose by 1 percentage point on the day of the rejection. The positive impact on timely payments declined on the following days before increasing again and peaking 11 days after the rejection at 2.4 percentage points, which could reflect the payment due date for that month. By the end of the two weeks after the rejection, timely payments by treated taxpayers became negative and significant, likely reflecting the severe bunching that preceded it. The path was smoother for late payments, which remained positive and significant for a few days, but at declining magnitudes.

The increase in the probability of paying VAT was significant both for large and SME taxpayers, but only SME taxpayers raised their amounts paid as well (Table 2). The point estimate for large taxpayers was three times as large as the one for SME taxpayers. While the probability of payment increased, there was no significant change in the amount paid among large taxpayers. Among SMEs taxpayers, the amount paid increased by 2.4 percentage points, statistically significant at the 10 percent level. The increase in amounts paid only among SME taxpayers could perhaps reflect that previous payments by large taxpayers were already more closely reflecting their real liabilities or that large taxpayers were more confident about their ability to defend such amounts in case of challenges by the tax administration.

This improvement in payment behavior is economically significant. The positive impact on VAT payments is remarkable because, in the first phase of the reform, the rationing algorithm was not yet factoring in tax arrears. So, that this improvement in compliance was not a mechanical effect of the reform. Extrapolating the increase in probability of payments and amounts paid to all the taxpayers treated and all the rejections that took place in 2018, the reform yielded 0.02 percent of GDP or around 0.7 percent of VAT collections. ${ }^{16}$

\footnotetext{
${ }^{16}$ Even if all the exit of taxpayers mentioned previously was explained by the reform, the net impact on VAT collections would still be positive at around 0.5 percent of total collections.
} 
The second phase of the reform was even more effective at inducing payments. On the day of the rejection, treated taxpayers became 4.3 percentage points more likely of making a payment of VAT than taxpayers in the control group, more than twice the payment response observed in the first phase of the reform. Unlike the previous phase, in this case the improvement was driven entirely by late payments (Figure 3, Panels C and D). As before, the impact on probability of payment was positive and significant both for SME and large taxpayers with large taxpayers responding more. Unlike the first phase of the reform, there was no significant impact on the amount paid for any group of taxpayers (Table 2). In sum, the addition of tax arrears to the algorithm was effective at raising VAT payments, particularly late ones, as the reform had intended.

Table 2. Impact on Tax Collections by Taxpayer Size

\begin{tabular}{|c|c|c|c|c|c|c|}
\hline & \multicolumn{3}{|c|}{ First Phase } & \multicolumn{3}{|c|}{ Second Phase } \\
\hline & Average & Large & SME & Average & Large & SME \\
\hline \multirow[t]{2}{*}{ Probability of Payment } & $0.001^{* \star *}$ & $0.003^{* \star *}$ & $0.001^{* \star *}$ & $0.005^{\star \star \star}$ & $0.007^{* \star \star}$ & $0.004^{\star \star \star}$ \\
\hline & $(0.000)$ & $(0.001)$ & $(0.000)$ & $(0.000)$ & $(0.003)$ & $(0.000)$ \\
\hline \multirow[t]{2}{*}{ Amount Paid (in logs) } & 0.016 & -0.075 & $0.024^{*}$ & 0.029 & -0.153 & 0.054 \\
\hline & $(0.013)$ & $(0.051)$ & $(0.013)$ & $(0.050)$ & $(0.199)$ & $(0.050)$ \\
\hline Number of Taxpayers & 31,366 & 1,466 & 29,900 & 2,924 & 112 & 2,812 \\
\hline Number of Observations & $27,790,276$ & $1,298,876$ & $26,491,400$ & $2,590,664$ & 99,232 & $2,491,432$ \\
\hline
\end{tabular}

Note: Probability of Payment measures the impact on the probability of payment in percentage points. Amount Paid is in log percentage points.

Standard errors clustered by taxpayer (in parenthesis). ${ }^{*} p<0.1{ }^{* *} p<0.05{ }^{* * *} p<0.01$.

Estimation at a daily frequency of specification

$Y_{i, t}=\beta I$ Treated $\left._{i, t}=1\right)+\kappa_{i}+\tau_{T(t)}+X_{i, t}+\varepsilon_{i, t}$ where $\tau_{T(t)}$ is a month fixed effect and $X_{i, t}$ includes a day-ofthe-week fixed effect. 


\section{Figure 3. Short-Term Impact on Tax Collections \\ Increase in the Probability of Payment \\ (in percentage points)}

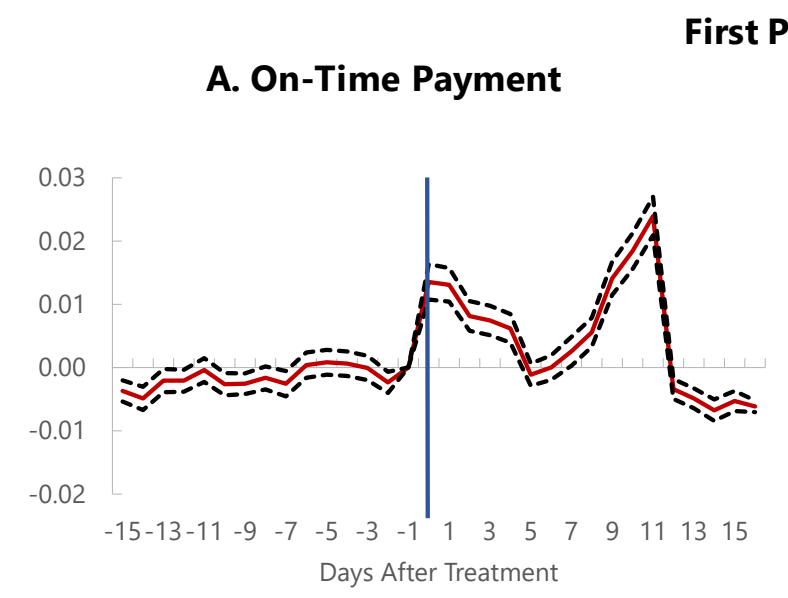

B. Late Payment

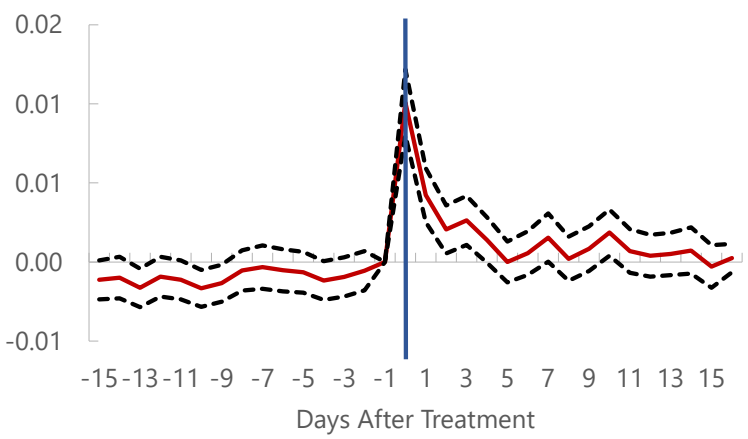

Second Phase

\section{On-Time Payment}

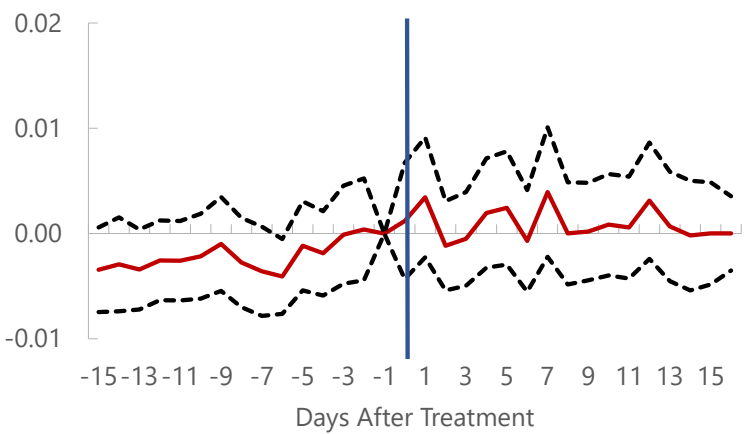

D. Late Payment

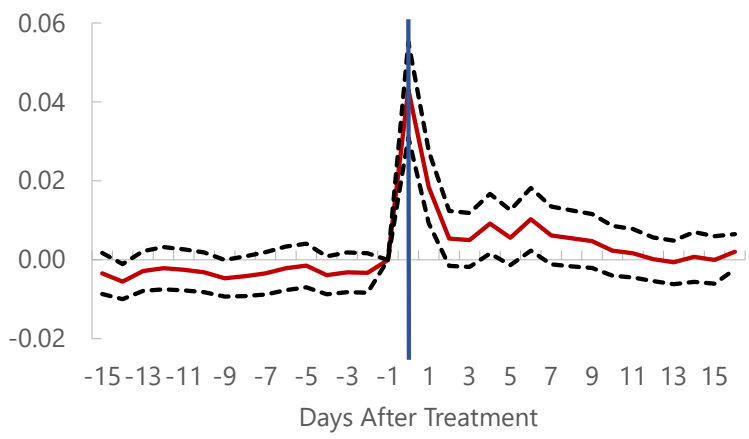

Note: Standard errors clustered by taxpayer. Dashed lines correspond to $95 \%$-level confidence intervals. Estimation at a daily frequency of specification $Y_{i, t}=\sum_{j=-16}^{17} \beta_{j} I$ (Treated $\left._{i, t+j}=1\right)+\kappa_{i}+\tau_{T(t)}+X_{i, t}+\varepsilon_{i, t}$ where $\tau_{T(t)}$ is a month fixed effect and $X_{i, t}$ includes a day-of-the-week fixed effect. Cumulative effects $\beta_{-16}$ and $\beta_{17}$ not shown.

\section{Tax Liabilities}

The first phase of the reform led to higher reporting of both input and output VAT (Figure 4, Panel A). On average, in the two months after the rejection, treated taxpayers reported higher output VAT by 12,741 Dominican pesos (USD 257), but at the same time higher input VAT by 10,042 Dominican pesos (USD 202), with respect to the control group. At 3-and 4-month horizons, input and output VAT kept growing at a similar pace. The net impact on tax liability was positive up to the third month and negative up to the fourth, but not statistically significant. Similar changes in input and output VAT are not uncommon, having been reported in previous studies (Bellon et al., 2019). Similar patterns for revenues and expenditures in income tax have also been found (Carrillo et al., 2017). They are suggestive of the taxpayers' efforts to reduce their 
tax liability by collecting further input VAT, in some way strengthening the VAT chain of selfenforcement over the long run, although over-declaration of input VAT or similar practices may have also contributed.

The second phase of the reform led to much higher input and output VAT, and a larger and significant positive impact on net VAT (Figure 4, Panel B). On average, in the two months after rejection, treated taxpayers reported higher output VAT for 96,900 Dominican pesos (USD 1,952), but at the same time higher input VAT for 38,668 Dominican pesos (USD 779). This led to higher net VAT for 49,780 Dominican pesos (USD 1,003) on average per taxpayer, highly statistically and economically significant. In the following months, output and input VAT kept growing, with the former increasing faster and inducing continuous and significant improvements in VAT liabilities. ${ }^{17}$

\section{Figure 4. Impact on VAT Liability}

\section{Cumulative Change}

(in Dominican pesos)

\section{A. First Phase}

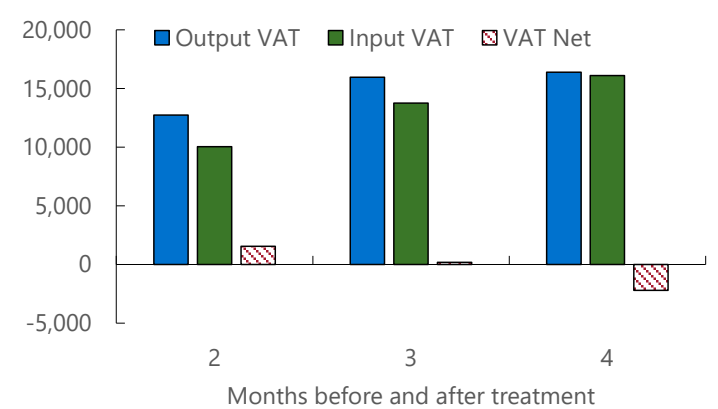

B. Second Phase

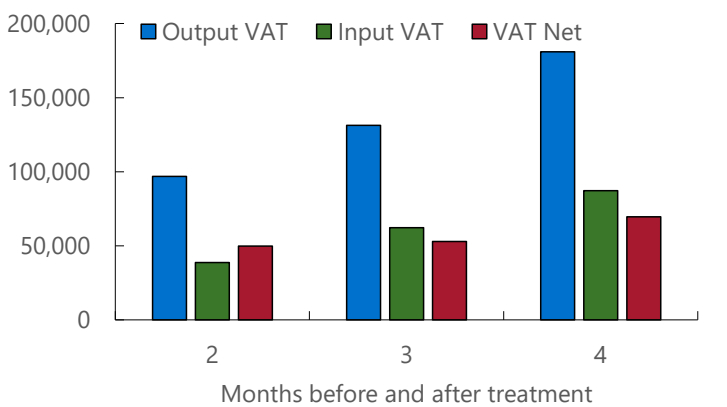

Note: The chart shows the $\beta$ coefficient from the regression $Y_{i, t}=\beta$ I Treate $\left._{i, t}=1\right)+\kappa_{i}+\tau_{t}+\varepsilon_{i, t}$ where $Y_{i, t}$ represents the sum of output, input, or net VAT over 2,3, and 4 months before and after treatment. Standard errors clustered at taxpayer level. Solid bars indicate significance at the $99 \%$ confidence level.

Dashed bars indicate no statistical significance.

There was a mild positive impact on income tax liability for SME taxpayers treated (Table 3). In the year following the rejection, there was no significant difference in revenues, expenditures, or net income declared on income tax returns. Yet, the point estimates were positive for revenues and net income. Income tax liability rose by 6.5 percentage points more for treated taxpayers than for those in the control group, an increase that was significant at the 10 percent confidence

\footnotetext{
${ }^{17}$ In both phases of the reform there was also a significant increase in the probability of amending previouslyfiled VAT returns.
} 
level. This response was entirely driven by SME taxpayers, as large taxpayers did not experience a significant change. ${ }^{18}$

Table 3. Impact on Income Tax Liability by Taxpayer Size

\begin{tabular}{lccc}
\hline & Average & Large & SME \\
\hline Revenues & 0.022 & 0.148 & 0.019 \\
& $(0.042)$ & $(0.197)$ & $(0.042)$ \\
Expenditures & & & \\
& -0.004 & 0.123 & -0.009 \\
& $(0.024)$ & $(0.084)$ & $(0.024)$ \\
Net Income & & & \\
& 0.054 & 0.043 & 0.053 \\
& $(0.042)$ & $(0.125)$ & $(0.043)$ \\
Income Tax & & & \\
& $0.065^{*}$ & -0.077 & $0.070^{*}$ \\
& $(0.038)$ & $(0.132)$ & $(0.039)$ \\
\hline Number of Taxpayers & 30,043 & 1,407 & 28,636 \\
Number of Observations & 42,481 & 1,713 & 40,768 \\
\hline
\end{tabular}

Note: Effects are shown in log percentage points.

Standard errors clustered by taxpayer (in parenthesis). ${ }^{*} p<0.1 * * p<0.05 * * * p<0.01$.

Sample trimmed at 1 and 99th percentile of revenues growth rate.

Estimation at an annual frequency of specification $Y_{i, t}=\beta$ I $\left._{\text {(reate }}{ }_{i, t}=1\right)+\kappa_{i}+\tau_{T(t)}+\varepsilon_{i, t}$ where $\tau_{T(t)}$ is a month-of-invoice-request fixed effect. It compares income tax returns submitted in the year before and after the invoice request.

\section{Information Reporting Obligations}

VAT taxpayers are required to send monthly information on their purchases (F606) and sales (F607) of goods and services to the DGII. These are electronic files detailing the information invoice by invoice to support information cross-checking efforts of the tax administration. The universe of taxpayers required to submit informative returns F606 and F607 is the total universe of VAT taxpayers $(234,856)$, which exacerbates control efforts of the DGII. Therefore, on-time filing rates of these informative returns are low, and particularly so for treated taxpayers before the reform. ${ }^{19}$

\footnotetext{
${ }^{18}$ We are unable to explore the impact on income tax liabilities for the second phase of the reform because our sample ends in February 2020, slightly over one year after the implementation of the second phase of the reform, and the deadline for filing annual income tax returns is around March and April.

19 The DGIl could benefit from moving gradually towards a regime focused on fewer taxpayers, those who, due to their size or position in the production-commercialization chain, can help to consolidate most of the VAT transactions. In fact, in many countries, these reporting obligations are limited to large taxpayers or those showing turnover above a certain level. There is a cost-benefit relationship between the number of informants and the information obtained. For example, it is expected that information quality to be higher for B2B transactions than for transaction with final consumers. The universalization of VAT information reporting obligations is neither usual nor recommended. It is much more difficult to applyan effective non-filing scheme, having the entire universe of VAT taxpayers as obliged to report.
} 
Treated taxpayers improved their provision of information to the revenue administration immediately. The probabilities of reporting past-due information returns on invoices received due to purchases and of invoices issued due to sales rose sharply upon treatment (Figure 5). They remained positive and significant for more than 10 days after the treatment, before becoming not statistically significant or weakly negative. A small negative pretrend suggests possible anticipation in this case too. The second phase of the reform produced similar dynamics, although more than twice as large (Figure A.2).

\section{Figure 5. Short-Term Impact on Compliance with Information Reporting Obligations - First Phase \\ Increase in the Probability \\ (in percentage points)}
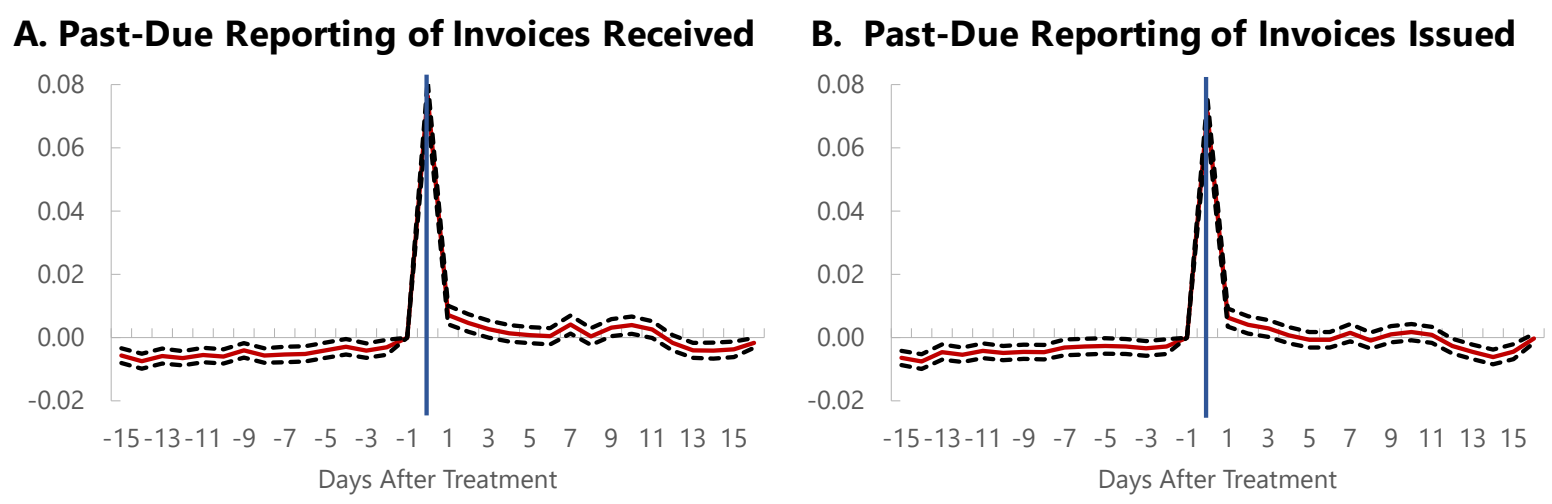

Note: Standard errors clustered by taxpayer. Dashed lines correspond to 95\%-level confidence intervals. Estimation at a daily frequency of specification $Y_{i, t}=\sum_{j=-16}^{17} \beta_{j} I$ (Treated $\left._{i, t+j}=1\right)+\kappa_{i}+\tau_{T(t)}+X_{i, t}+\varepsilon_{i, t}$ where $\tau_{T(t)}$ is a month fixed effect and $X_{i, t}$ includes a day-of-the-week fixed effect. Cumulative effects $\beta_{-16}$ and $\beta_{17}$ not shown.

The reform narrowed the noncompliance gap of treated taxpayers (Table 4). The first phase of the reform led to an increase in the probability of timely reporting of invoices received by 5.2 percentage points, compared to an initial gap of 1.6 percent (Table 1). The probability of timely reporting invoices issued increased by 18.7 percent among treated taxpayers, almost completely reversing the initial gap of 20.2 percent (Table 1). The filing of past-due information returns on invoices received also rose, whereas the past-due reporting of invoices issued dropped, reflecting the large improvement in timely filing. The second phase of the reform had a larger impact on past-due reporting. The improvement of compliance with filing of VAT information returns was significant both for large and SME taxpayers. 
Table 4. Medium-Term Impact on Compliance with Information Reporting Obligations

Increase in the Probability

(in percentage points)

\begin{tabular}{|c|c|c|c|c|c|c|}
\hline & \multicolumn{3}{|c|}{ First Phase } & \multicolumn{3}{|c|}{ Second Phase } \\
\hline & Average & Large & SME & Average & Large & SME \\
\hline On-Time Reporting of Invoices Received & $\begin{array}{c}0.052^{\star \star \star} \\
(0.004)\end{array}$ & $\begin{array}{c}0.083^{\star \star \star} \\
(0.020)\end{array}$ & $\begin{array}{c}0.050 \text { *** } \\
(0.004)\end{array}$ & $\begin{array}{c}0.026^{\star \star \star} \\
(0.007)\end{array}$ & $\begin{array}{l}-0.004 \\
(0.044)\end{array}$ & $\begin{array}{c}0.027^{\star \star \star} \\
(0.007)\end{array}$ \\
\hline On-Time Reporting of Invoices Issued & $\begin{array}{c}0.187^{\star \star \star} \\
(0.003)\end{array}$ & $\begin{array}{c}0.284^{\star \star *} \\
(0.019)\end{array}$ & $\begin{array}{c}0.183^{\star \star \star} \\
(0.003)\end{array}$ & $\begin{array}{c}0.041^{\star * \star} \\
(0.007)\end{array}$ & $\begin{array}{c}0.063 \\
(0.042)\end{array}$ & $\begin{array}{c}0.039 * \star * \\
(0.007)\end{array}$ \\
\hline Past-Due Reporting of Invoices Received & $\begin{array}{c}0.028^{* * *} \\
(0.004)\end{array}$ & $\begin{array}{l}0.037^{\star} \\
(0.020)\end{array}$ & $\begin{array}{c}0.029 * * * \\
(0.004)\end{array}$ & $\begin{array}{c}0.193^{* * *} \\
(0.011)\end{array}$ & $\begin{array}{c}0.203^{\star * *} \\
(0.057)\end{array}$ & $\begin{array}{c}0.194^{\star * *} \\
(0.011)\end{array}$ \\
\hline Past-Due Reporting of Invoices Issued & $\begin{array}{c}-0.080^{* * *} \\
(0.004)\end{array}$ & $\begin{array}{c}-0.138^{* * *} \\
(0.021)\end{array}$ & $\begin{array}{c}-0.077^{* * *} \\
(0.004)\end{array}$ & $\begin{array}{c}0.208^{* * *} \\
(0.011)\end{array}$ & $\begin{array}{c}0.168^{\star * *} \\
(0.056)\end{array}$ & $\begin{array}{c}0.211^{\star * *} \\
(0.011)\end{array}$ \\
\hline Number of Taxpayers & 31,366 & 1,466 & 29,900 & 2,924 & 112 & 2,812 \\
\hline Number of Observations & 940,980 & 43,980 & 897,000 & 87,720 & 3,360 & 84,360 \\
\hline
\end{tabular}

Note: Effects are shown in percentage points.

Standard errors clustered by taxpayer (in parenthesis). ${ }^{*} p<0.1{ }^{* *} p<0.05^{* * *} p<0.01$.

Estimation at a monthly frequency with specification $\left.Y_{i, t}=\beta I \operatorname{Irreated}_{i, t}=1\right)+\kappa_{i}+\tau_{T(t)}+X_{i, t}+\varepsilon_{i, t}$ where

$\tau_{T(t)}$ is a month fixed effect and $X_{i, t}$ includes a cubic trend interacted by a dummyidentifying whether the

taxpayer was in the treatment or control group.

\section{CONCLUSION}

In a region where the integrity of invoices circulating in the economy is a major concern for tax administrations, we study a reform in the Dominican Republic that introduced risk-based rationing of invoices. High-risk taxpayers were denied invoices or granted approval for only a fraction of the invoices requested until they regularize their situation. We find that the reform led to significant and persistent improvements in compliance with filing and reporting obligations in VAT and income tax, higher VAT collections, and a modest increase in reported VAT and income tax liabilities.

Besides the short-term impact on tax collection, the reform was important because it strengthened the VAT self-enforcing chain by enhancing the incentives for taxpayers to collect invoices from their purchases. This is likely to have a positive impact on VAT collection over time and to reduce the potential for fraudulent practices associated with fake invoices. In addition, higher compliance with filing and information reporting obligations gives more information to the tax administration to improve enforcement in other areas such as crosschecking data with third-party information, inspections, audits, and notifications. 
Finally, while this reform was enacted in a paper-based invoice system, it can easily be extended to e-invoice systems. In fact, e-invoice regimes simplify the procedures and reduce the costs of compliance, mitigating the negative impact on taxpayers, especially small ones, of the additional control by the tax administration. 


\section{REFERENCES}

Artana, D. and I. Templado. 2018. "Análisis del Impacto de la Factura Electrónica en la Argentina." Inter-American Development Bank Discussion Paper No. 562. Inter-American Development Bank, Washington, DC.

Barreix, A.D. and R. Zambrano. eds. 2018. "Electronic Invoicing in Latin America." Inter-American Development Bank, Washington, DC.

Bellon, M., J. Chang, E. Dabla-Norris, S. Khalid, F. Lima, E. Rojas, and P. Villena. 2019. "Digitalization to Improve Tax Compliance: Evidence from VAT E-invoicing in Peru." IMF Working Paper 19/231. International Monetary Fund, Washington, DC.

Bérgolo, M., R. Ceni, and M. Sauval. 2018. "Factura Electrónica y Cumplimiento Tributario: Evidencia a partir de un Enfoque Cuasi-experimental." Inter-American Development Bank Discussion Paper No. 561. Inter-American Development Bank, Washington, DC.

Cardoza, M and N. Aybar. 2014. "Fiscal Invoices: The Dominican Republic Experience." CIAT/AEAT/IEF Tax Administration Review 36: 22-40.

Carrillo, P., D. Pomeranz, and M. Singhal. 2017. "Dodging the Taxman: Firm Misreporting and Limits to Tax Enforcement." American Economic Journal: Applied Economics, 9 (2): 144-64.

Casey P. and P. Castro. 2015. "Electronic Fiscal Devices (EFDs): An Empirical Study of their Impact on Taxpayer Compliance and Administrative Efficiency." IMF Working Paper 15/73. International Monetary Fund, Washington, DC.

Castro, H. J. F., A. Z. Carrillo, S. B. Cortés, G. A. Aragón, and M. E. S. Diez. 2016. "Impacto en la Evasión por la Introducción de la Factura Electrónica." Instituto Tecnológico y de Estudios Superiores de Monterrey. No. IA-006E00002-E37-2016.

Chetty, R., A. Looney, and K. Kroft. 2009. "Salience and Taxation: Theory and Evidence." American Economic Review, 99 (4): 1145-77.

Chirico, M., R. Inman, C. Loeffler, J. MacDonald, and H. Sieg. 2016. "An Experimental Evaluation of Notification Strategies to Increase Property Tax Compliance: Free-Riding in the City of Brotherly Love." Tax Policy and the Economy, 30 (1): 129-61.

Clarke, D. and K. Schythe. 2020. "Implementing the Panel Event Study." IZA Institute of Labor Economics. IZA Discussion Paper No. 13524. IZA, Bohn, Germany.

Dirección General de Impuestos Internos (DGII). 2018. Norma General No. 06-2018. DGII, Santo Domingo, Dominican Republic. 
Dirección General de Impuestos Internos (DGII). 2019. "Efecto del Cambio de Secuencia de Comprobantes (Norma No. 06-2018) sobre las Recaudaciones y el Cumplimiento Tributario." Unpublished.

Ebrill, L. P., M. Keen, M., and V. J. Perry. 2001. "The Modern VAT." International Monetary Fund, Washington, DC. Retrieved Jul 19, 2021, from https://www.elibrary.imf.org/view/books/071/07173-9781589060265-en/ch09.xml

Naritomi, J. 2019. "Consumers as Tax Auditors." American Economic Review, 109 (9): 3031-72.

Okunogbe, O., and V. Pouliquen. 2018. "Technology, Taxation, and Corruption: Evidence from the Introduction of Electronic Tax Filing." World Bank Policy Research Working Paper No. 8452. World Bank Group, Washington, DC.

Pomeranz, D. 2015. "No Taxation without Information: Deterrence and Self-Enforcement in the Value Added Tax." American Economic Review, 105 (8): 2539-69.

Ramírez, J., N. Oliva, and M. Andino. 2018. "Facturación Electrónica en Ecuador: Evaluación de Impacto en el Cumplimiento Tributario". Inter-American Development Bank Discussion Paper No. 563. Inter-American Development Bank, Washington, DC.

Russell, B. 2010. "Revenue Administration: Developing a Taxpayer Compliance Program." IMF Technical Notes and Manuals 10/17. International Monetary Fund, Washington, DC.

Slemrod, J. 2019. "Tax Compliance and Enforcement." Journal of Economic Literature, 57(4): 904954.

Tax Administration Diagnostic Assessment Tool (TADAT) Secretariat. 2019. "Field Guide." April 2019 Edition. 


\section{APPENDIX}

\section{A. Filing Obligations in the Second Phase of the Reform}

The second phase of the reform also led to an immediate improvement in compliance with VAT filing obligations (Figure A.1, Panel A). The probability of filing past-due VAT returns shows a very similar dynamic around the time of the rejection than in the first phase of the reform, albeit the magnitudes are larger. Whereas in the first phase of the reform the improvement in probability of filing past-due VAT returns was around 10 percentage points, in the second phase it reached almost 30 percentage points.

The probability of filing income tax returns rose significantly on the day of treatment (Figure A.1, Panel B). The probability of filing an original income tax return rose by 5.3 percentage points on the day of the rejection, but became not significant from zero afterwards.

The improvement persisted over the medium term. Treated taxpayers increased their timely filing of VAT returns by 9.7 percentage points in the month of the rejection, an improvement that remained stable and significant for the following six months (Figure A.1, Panel C). The filing of past-due VAT returns also increased sharply in the month of the rejection. While it declined afterwards, it remained positive and significant (Figure A.1, Panel D). 
Figure A.1. Impact on Compliance with Filing Obligations - Second Phase

Increase in the Probability of Filing

(in percentage points)
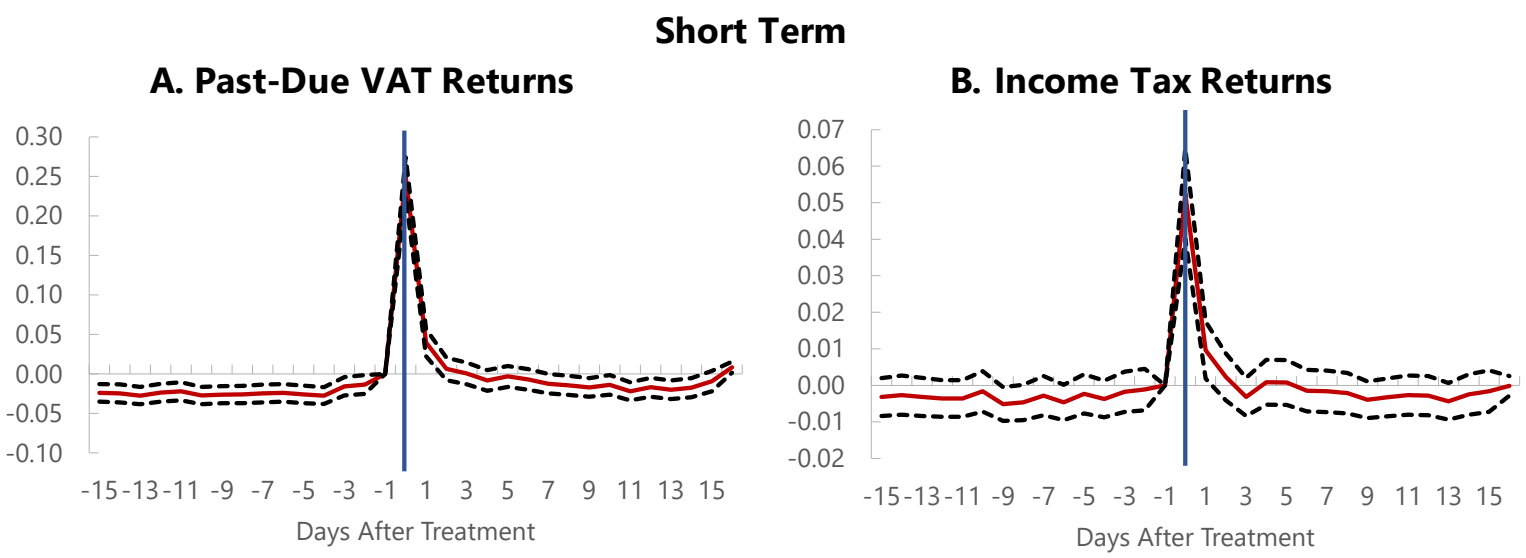

C. On-Time VAT Returns

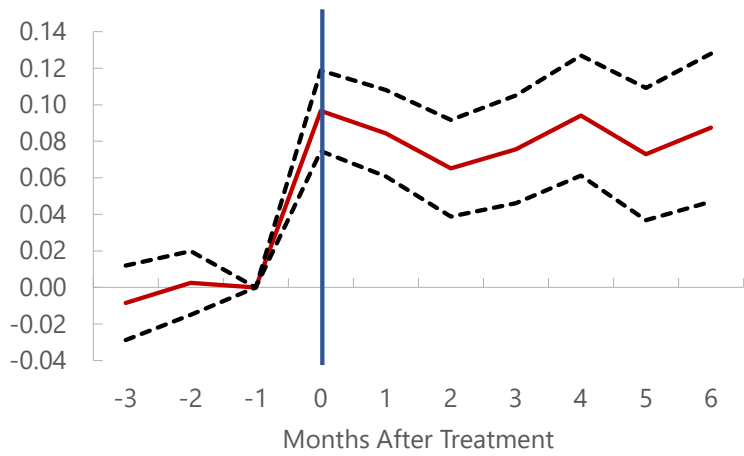

\section{Medium Term}

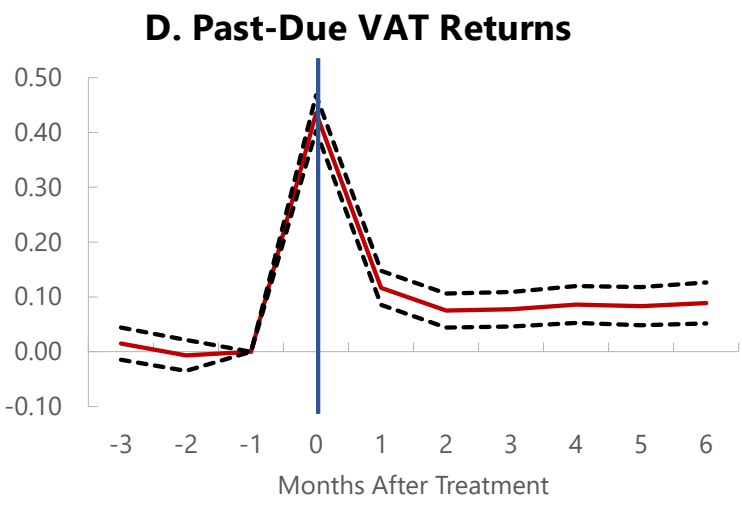

Note: Standard errors clustered by taxpayer. Dashed lines correspond to $95 \%$-level confidence intervals.

The short-term results of Panels $\mathrm{A}$ and $\mathrm{B}$ are estimated at a daily frequency with specification $Y_{i, t}=$

$\sum_{j=-16}^{17} \beta_{j} I$ Treated $\left._{i, t+j}=1\right)+\kappa_{i}+\tau_{T(t)}+X_{i, t}+\varepsilon_{i, t}$ where $\tau_{T(t)}$ is a month fixed effect and $X_{i, t}$ includes a dayof-the-week fixed effect. Cumulative effects $\beta_{-16}$ and $\beta_{17}$ not shown.

The medium-term results of Panels $C$ and $D$ are estimated at a monthly frequency with specification $Y_{i, t}=$ $\sum_{j=-4}^{7} \beta_{j} I\left(\right.$ Treated $\left._{i, t+j}=1\right)+\kappa_{i}+\tau_{T(t)}+X_{i, t}+\varepsilon_{i, t}$ where $\tau_{T(t)}$ is a month fixed effect and $X_{i, t}$ includes a cubic trend interacted by a dummy identifying whether the taxpayer was in the treatment or control group.

Cumulative effects $\beta_{-4}$ and $\beta_{7}$ not shown.

\section{B. Information Reporting Obligations in the Second Phase of the Reform}

Compliance with information returns rose by more than in the first phase of the reform (Figure A.2). The probability of filing information returns rose sharply on the day of the rejection for treated taxpayers. The increase on the day of the rejection was around 20 percentage points both for returns on invoices received and issued. The response declined soon afterwards. 


\section{Figure A.2. Short-Term Impact on Compliance with Information Reporting Obligations - Second Phase \\ Increase in the Probability \\ (in percentage points)}

\section{A. Past-Due Reporting of Invoices Received}

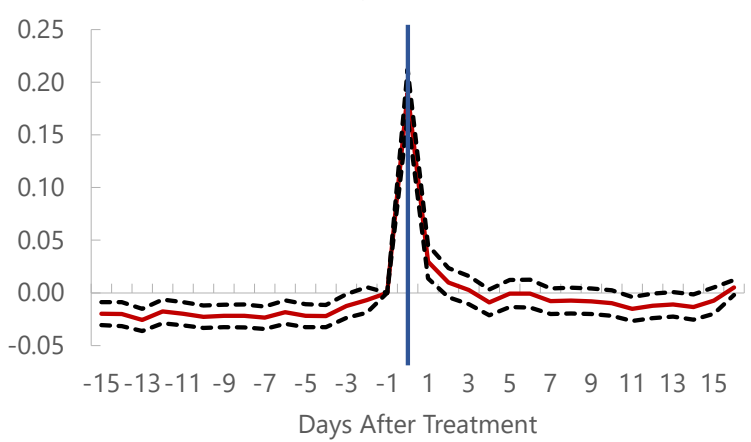

B. Past-Due Reporting of Invoices Issued

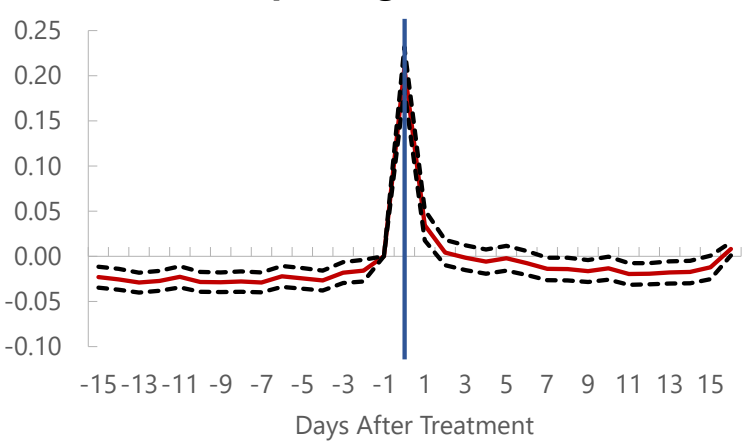

Note: Standard errors clustered by taxpayer. Dashed lines correspond to $95 \%$-level confidence intervals. Estimation at a daily frequency of specification $Y_{i, t}=\sum_{j=-16}^{17} \beta_{j} I$ (Treated $\left._{i, t+j}=1\right)+\kappa_{i}+\tau_{T(t)}+X_{i, t}+\varepsilon_{i, t}$ where $\tau_{T(t)}$ is a month fixed effect and $X_{i, t}$ includes a day-of-the-week fixed effect. Cumulative effects $\beta_{-16}$ and $\beta_{17}$ not shown.

\section{Robustness}

In this section, we present some robustness analysis. In particular, we explore a coarser and a broader definition of treatment, in addition to allowing for industry-specific time trends.

Our results on improved compliance are robust to a coarser definition of treatment, whereby only taxpayers with two requests rejected are considered treated in the first phase of the reform. In this case, taxpayers with only one request for invoices rejected are dropped from the analysis. We find that the dynamics around the time of rejection are quite similar to those estimated in the baseline, with point estimates for compliance with filing, payment, and reporting obligations being slightly higher (Figure A.3). 
Figure A.3. Short-Term Impact on Compliance - Coarser Definition of Treatment

Increase in the Probability

(in percentage points)

\section{A. Filing Past-Due VAT Returns}

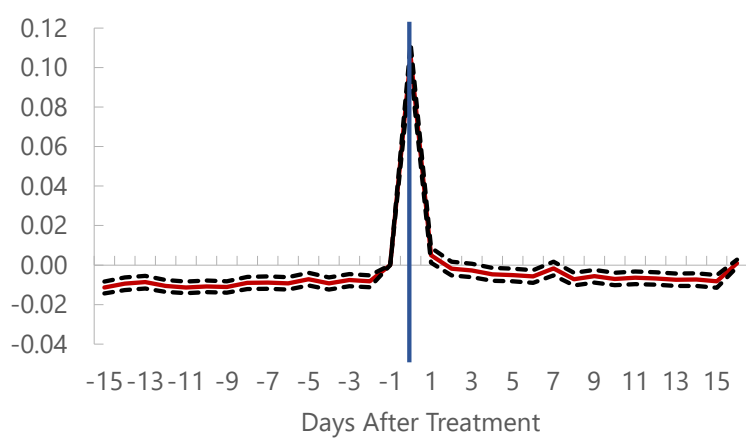

C. Past-Due Reporting of Invoices Received

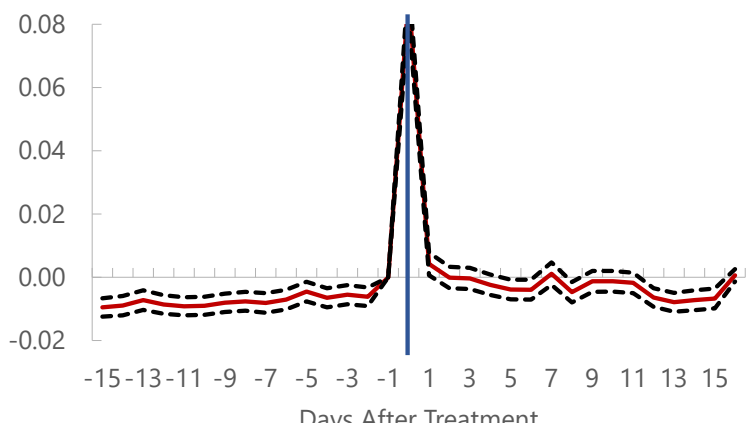

B. Late VAT Payment

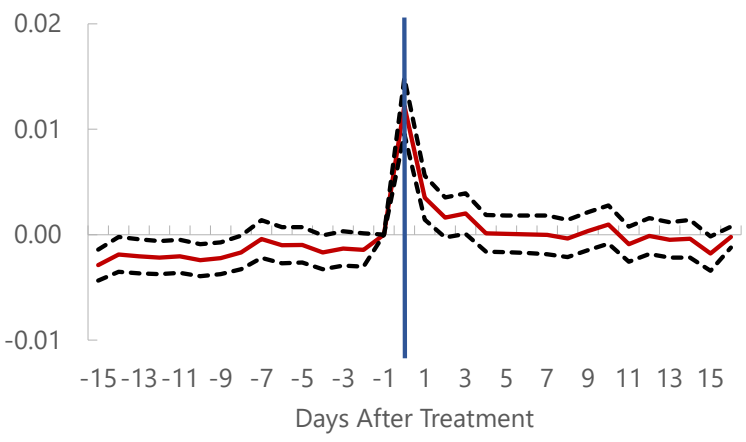

D. Past-Due Reporting of Invoices Issued

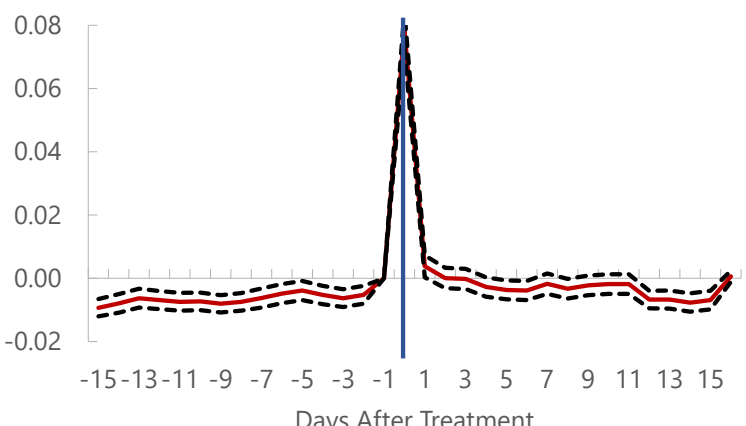

Note: Standard errors clustered by taxpayer. Dashed lines correspond to 95\%-level confidence intervals. Estimation at a daily frequency of specification $Y_{i, t}=\sum_{j=-16}^{17} \beta_{j} I$ (Treated $\left._{i, t+j}=1\right)+\kappa_{i}+\tau_{T(t)}+X_{i, t}+\varepsilon_{i, t}$ where $\tau_{T(t)}$ is a month fixed effect and $X_{i, t}$ includes a day-of-the-week fixed effect. Cumulative effects $\beta_{-16}$ and $\beta_{17}$ not shown.

Taxpayers who got more than two invoice requests rejected are considered treated under this specification. Taxpayers who got only one rejection are dropped from the analysis.

Our results are also robust to a broader definition of treatment, whereby even taxpayers who got fewer than five invoices approved are considered treated in the first phase of the reform. In this way, we include in the treatment group taxpayers whose first request for invoices was not rejected, but that got so few invoices approved that in all likelihood had to return to the tax administration for additional invoices shortly afterwards. The dynamics and magnitudes around the time of treatment remain very similar to our baseline estimates (Figure A.4). 
Figure A.4. Short-Term Impact on Compliance - Broader Definition of Treatment

Increase in the Probability

(in percentage points)

\section{A. Filing Past-Due VAT Returns}

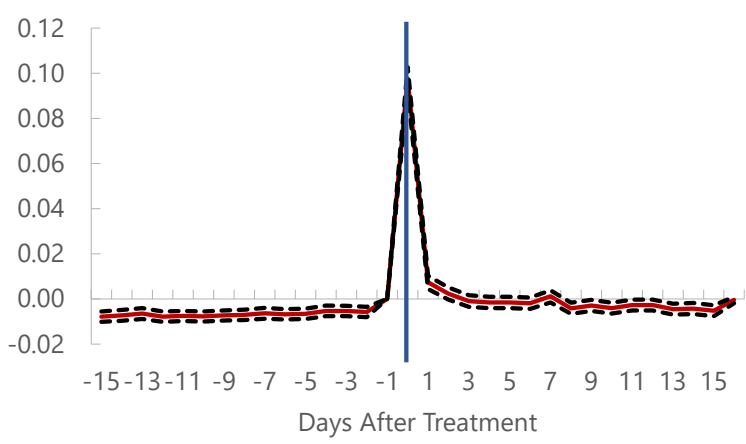

C. Past-Due Reporting of Invoices Received

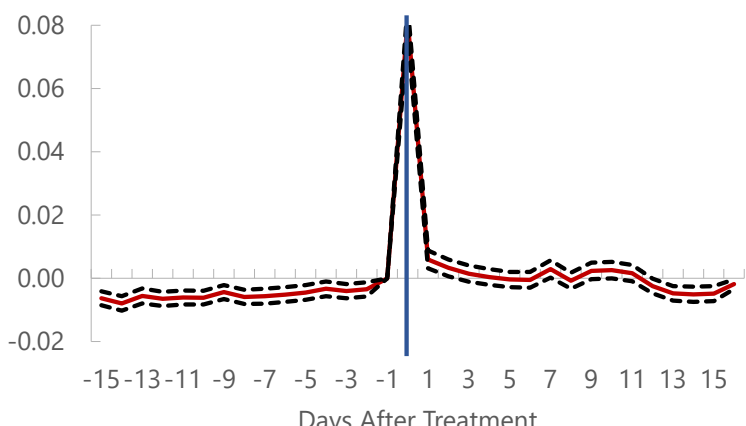

B. Late VAT Payment

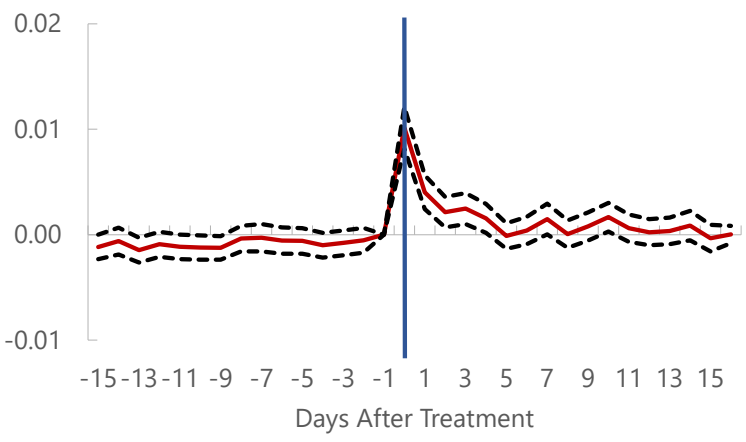

D. Past-Due Reporting of Invoices Issued

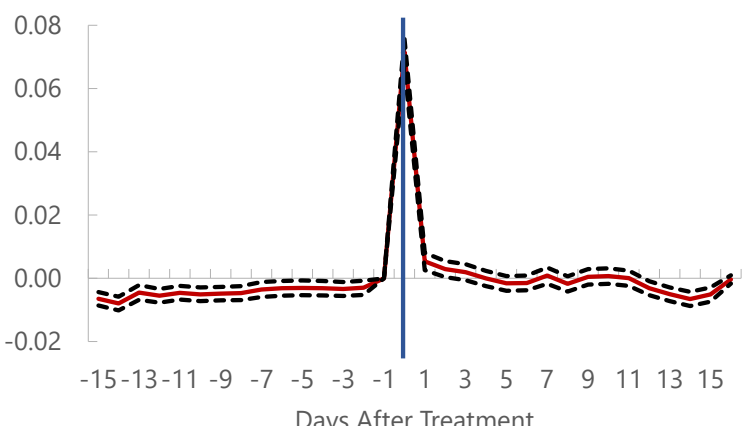

Note: Standard errors clustered by taxpayer. Dashed lines correspond to 95\%-level confidence intervals. Estimation at a daily frequency of specification $Y_{i, t}=\sum_{j=-16}^{17} \beta_{j} I$ (Treated $\left._{i, t+j}=1\right)+\kappa_{i}+\tau_{T(t)}+X_{i, t}+\varepsilon_{i, t}$ where $\tau_{T(t)}$ is a month fixed effect and $X_{i, t}$ includes a day-of-the-week fixed effect. Cumulative effects $\beta_{-16}$ and $\beta_{17}$ not shown.

Taxpayers who got fewer than five invoices approved are considered treated under this specification.

Finally, our results are robust to heterogeneous time trends by industry. We are already selecting taxpayers into the control group aiming to resemble the composition of the treatment group in terms of industry, region, and size, so that the common time trend should capture industryspecific dynamics reasonably well. Nevertheless, we still try a more flexible specification of time trends by estimating our specification with industry-by-month time fixed effects. Our results are broadly unchanged (Figure A.5). 


\section{Figure A.5. Short-Term Impact on Compliance - Heterogeneous Time Trends by Industry Increase in the Probability \\ (in percentage points)}

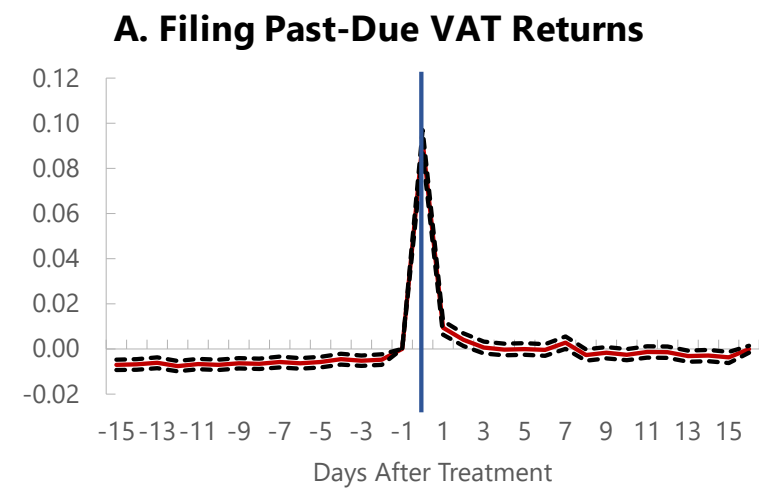

\section{Past-Due Reporting of Invoices Received}
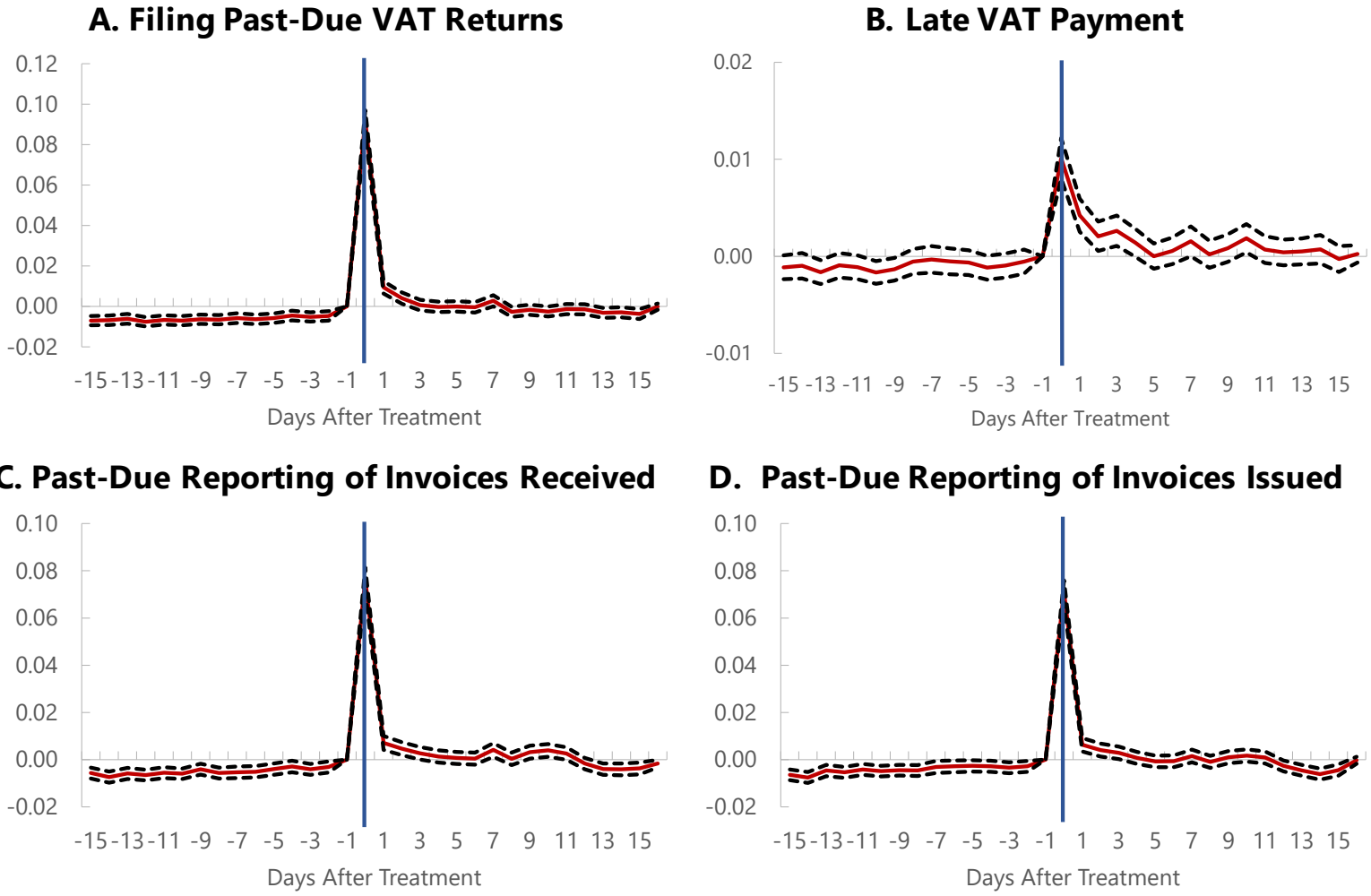

Note: Standard errors clustered by taxpayer. Dashed lines correspond to $95 \%$-level confidence intervals. Estimation at a daily frequency of specification $Y_{i, t}=\sum_{j=-16}^{17} \beta_{j} I$ (Treated $\left._{i, t+j}=1\right)+\kappa_{i}+\tau_{T(t)}+X_{i, t}+\varepsilon_{i, t}$ where $\tau_{T(t)}$ is a month fixed effect and $X_{i, t}$ includes a day-of-the-week fixed effect and industry-by-month time fixed effects. Cumulative effects $\beta_{-16}$ and $\beta_{17}$ not shown. 